\title{
VARIABILIDADES E TENDÊNCIAS CLIMÁTICAS NOS MÁXIMOS DO INVERNO E VERÃO NO BRASIL
}

\author{
PENEREIRO, Júlio César - jcp@puc-campinas.edu.br \\ Pontifícia Universidade Católica de Campinas/ PUC-Campinas \\ MESCHIATTI, Monica Cristina - monicasenna@id.uff.br \\ Centro de Ecofisiologia e Biofísica do Instituto Agronômico de Campinas / IAC- \\ Campinas
}

\begin{abstract}
RESUMO: As mudanças climáticas observadas em diferentes escalas têm atraído o interesse de muitos pesquisadores nas últimas décadas. Alterações nos padrões diário, mensal e sazonal de temperaturas do ar e de precipitação pluviométrica podem afetar as mais diversas atividades humanas. O objetivo desse estudo foi identificar tendências climáticas em séries anuais de junho e dezembro de precipitação pluvial e temperaturas máxima, mínima e média do ar de 243 localidades espalhadas pelo Brasil. Os meses de junho e dezembro representam os picos de temperatura de inverno e verão, respectivamente. A montagem das séries foi realizada por meio de dados diários pertencentes ao Instituto Nacional de Meteorologia. O período analisado varia em cada localidade de acordo com a disponibilidade dos dados. A análise de tendências foi realizada por meio de testes não paramétricos de Mann-Kendall e Pettitt. $O$ teste de Mann-Kendall permitiu verificar os pontos de mudança no comportamento das séries, indicando o início da tendência, enquanto o teste de Pettitt permitiu observar em que ano ocorreu tal ruptura. Os resultados foram apresentados por meio de gráficos dos testes estatísticos, mapas do Brasil de distribuições de tendências e gráficos regionais de frequências temporal. Os histogramas mostraram que, em junho, as maiores quantidades de tendências nas temperaturas do ar e precipitação foram observadas na primeira década do século XXI e, em dezembro, as maiores quantidades de tendências foram registradas no final do século $X X$.
\end{abstract}

Palavras- chaves: Tendências climáticas, testes estatísticos, frequência temporal, regiões brasileiras.

\section{CLIMATE VARIABILITY AND TRENDS IN PEAK WINTER AND SUMMER IN BRAZIL}

ABSTRACT: Climate changes observed in many different ranges have attracted much attention from scientists during the last decades. Changes in daily, monthly and seasonal patterns of air temperatures and precipitation can affect many human activities. The aim of this study was to identify climate trends in annual series of June and December regarding precipitation and maximum, minimum and average air temperature of 243 localities in Brazil. The months of June and December represent the winter and summer temperature peaks, respectively. The series were generated through daily data from the Meteorology National Institute. The range of the series depended on the availability in each locality. The trend analysis was performed by means of Mann-Kendall and Pettitt non-parametric tests. The Mann-Kendall test allowed to verify the abrupt changes in the series behaviour, indicating the beginning of the trend, whereas Pettitt test allowed to observe in which year this rupture happened. The results were presented by means of graphics of the statistical tests, Brazilian maps with distributions of trends and regional temporal frequencies graphs. The histograms showed that, in June, largest quantities of trends in air temperature and precipitation were observed at the first decade of the XXI century and, in December, the largest quantities of trends were observed at the end of the XX century.

Keywords: Climatic trends, statistical tests, time frequency, Brazilian regions. 


\section{INTRODUÇÃO}

Uma das grandes preocupações do meio científico-acadêmico nas últimas décadas são as mudanças climáticas e suas consequências em relação a todas as implicações de âmbito social, econômico e ambiental. Essas preocupações voltadas às alterações climáticas devem-se ao fato que o clima do planeta vem apresentando variações bastante acentuadas, principalmente desde meados do século passado (IPCC, 2014).

Neste contexto, o Painel Intergovernamental das Mudanças Climáticas (IPCC) comenta, em seu Quinto Relatório Científico (AR5/IPCC, 2014), que o aumento da temperatura atmosférica é inequívoco e, desde a década de 1970, são observadas variações nos padrões climáticos globais. Este documento relata também que a temperatura média da atmosfera tem aumentado em quase todo o globo, com incrementos de até $2,5^{\circ} \mathrm{C}$ no período de 1901 a 2012 nas regiões sul da América do Sul, norte da África, central do continente asiático e norte da América do Norte. Além disso, aumentos na precipitação pluviométrica anual de até $50 \mathrm{~mm}$.ano-1.década-1 foram observados no sul da América do Sul e América do Norte, norte da Austrália e norte da Europa. Tendências negativas nessa variável foram observadas na África, sul do continente asiático e sul europeu, com diminuição de 5 a 50 mm.ano-1.década-1 (IPCC, 2014).

No entender de Alexander et al. (2006), ao analisar dados de 2000 estações medidoras de temperaturas e 2200 de precipitação pluvial espalhadas pelo mundo, foi possível identificar, em séries anuais, tendências significativas de aumento nas temperaturas na América do Sul, especialmente na segunda metade do século XX. Não obstante, Doyle e Barros (2011) observaram aumento de $55 \mathrm{~mm}$ por ano na precipitação anual da região da Bacia do Rio da Prata. No entanto, Haylock et al. (2006) realizaram análises de dados observados para o Brasil, entre 1960 e 2000, e identificaram tendências positivas na precipitação pluviométrica no Sul e Sudeste, e tendências negativas no Nordeste do país.

Para os índices relativos à temperatura mínima, de acordo com a Equipe de Peritos sobre Deteç̧ão e Índices de Mudança de Climática (na sigla em inglês, ETCCDI - Expert Team on Climate Change Detection and Indices), (ETCCDI, 2016), Alexander et al. (2006) analisaram dados de mais de 1400 estações meteorológicas, quando puderam verificar tendências de aumento em $70,0 \%$ das regiões continentais analisadas, incluindo a América do Sul. Tendências em temperaturas extremas, inferidas entre 1960 e 2000 nesse continente também foram identificadas por Vincent et al. (2005). De acordo com esses autores, observou-se tendência de aumento na temperatura mínima extrema anual. Neste contexto, Marengo e Camargo (2008) observaram que os eventos extremos de temperatura no Brasil, especialmente na região Sul, podem ser influenciados pelo aumento na frequência de ocorrência de eventos climáticos extremos. Esses pesquisadores identificaram que a partir de 1960 as temperaturas do ar máximas e mínimas, em cada escala anual e sazonal, têm mudado no sul do Brasil. De forma geral, observou-se acentuada tendência de aumento na temperatura mínima quando comparado com a tendência de aumento na temperatura máxima, tanto em escala anual como durante o verão e o inverno (MARENGO; CAMARGO, 2008).

Outros estudos de análise de dados anuais de temperaturas do ar foram realizados no sul do Brasil sendo que, no período de 1913 a 2006, foi constatado 
aumento de $0,5^{\circ} \mathrm{C}$ por década na temperatura mínima (SANSIGOLO; KAYANO, 2010). Essa variável climática, no estado de São Paulo, também exibiu tendência positiva no período de 1951 a 2010 (BLAIN, 2011) e no período 1890 a 2010 (BLAIN; LULU, 2011).

Diante do exposto, observa-se que as questões referentes às mudanças climáticas em escala local, regional ou global têm atraído o interesse de muitos pesquisadores nas últimas décadas. Alterações nos padrões diário, semanal, mensal, sazonal e/ou anual de temperaturas do ar e de precipitação pluviométrica podem afetar as mais diversas atividades humanas, principalmente, aquelas relacionadas à economia, ao meio ambiente e ao planejamento de outras atividades.

Neste sentido, o objetivo do presente trabalho foi avaliar as variabilidades e identificar possíveis tendências significativas em séries temporais de temperaturas mínima, média e máxima e precipitação pluviométrica observadas em municípios brasileiros especificamente nos meses de junho e dezembro, com períodos variados. As análises dos indícios de alterações bruscas e da data aproximada de tal evento foram realizadas por meio dos testes não paramétricos de Mann Kendall e Pettitt.

\section{MATERIAIS E MÉTODOS}

\section{1. ÁREA DE ESTUDO E DADOS TRATADOS}

O Brasil possui uma área com aproximadamente $8.515 .767,049 \mathrm{~km}^{2}$, estando localizado entre as longitudes $-75^{\circ}$ e $-35^{\circ}$, e latitudes $5^{\circ}$ e $-30^{\circ}$. De acordo com o Instituto Brasileiro de Geografia e Estatística (IBGE), o país possui uma população de 206,473 milhões de habitantes, um total de 5569 municípios, além do Distrito Federal, que estão espalhados por cinco grandes regiões políticas, a saber: Sul, Sudeste, Centro-Oeste, Norte e Nordeste (IBGE, 2010).

De acordo com o Painel Brasileiro de Mudanças Climáticas (PBMC), por ser um país de dimensões continentais, o Brasil apresenta uma grande diversidade de regimes climáticos e de influências sobre seu clima, o que certamente dificulta a aquisição de séries de dados observacionais de períodos mais longos, cobrindo, por exemplo, o início do século XX (PBMC, 2013).

No presente estudo foram utilizadas séries temporais de dados anuais dos meses de junho e dezembro, em períodos diferenciados, de temperaturas do ar máxima (T-Máx.), média ( $T$-Méd.) e mínima ( $T$-Mín.) e de precipitação pluviométrica (Prec.) de 243 municípios brasileiros, sendo 25 capitais dos estados. A montagem dessas séries foi realizada por meio de dados diários pertencentes ao Banco de Dados Meteorológicos para Ensino e Pesquisa (BDMEP) do Instituto Nacional de Meteorologia (INMET, 2016).

Os meses de junho e dezembro foram escolhidos por representarem, respectivamente, o início do inverno e verão. Nesses meses comumente se registram os valores medianos de temperatura máxima e temperatura mínima.

O BDMEP é um banco de dados que contém informações que apoiam, além das atividades de ensino e pesquisa, outras aplicações em Meteorologia, Hidrologia, Recursos Hídricos, Saúde Pública e Meio Ambiente. Os referidos dados são abrigados digitalmente, de acordo com as normas técnicas 
internacionais da Organização Meteorológica Mundial (OMM), referentes às séries temporais da rede de estações medidoras do INMET. Até a presente data, novembro de 2016, o BDMEP conta com 266 estações meteorológicas convencionais, sendo que os dados diários estão disponíveis a partir de 01 de janeiro de 1961. Ressalta-se que, como o BDMEP não disponibiliza dados diários da T-Méd. neste trabalho decidiu-se calcular essa variável a partir da média aritmética diária entre T-Mín. e T-Máx.

O mapa representado pela Figura 1 mostra a distribuição espacial de todas as estações medidoras do INMET. Verifica-se que em algumas regiões do Brasil não existem estações meteorológicas instaladas, como se observa no estado de Rondônia, no oeste do estado do Mato Grosso, no sul dos estados do Pará e do Amazonas. Além disso, as capitais Campo Grande (MS) e Porto Velho (RO) não possuem estações medidoras do INMET, portanto não fazem parte do levantamento climático aqui abordado.

As 243 localidades selecionadas no presente estudo envolvem 91,35\% do total de estações do INMET, apresentadas em azul na Figura 1, sendo que 40 (15,04\%) encontram-se na região Norte, 90 (33,83\%) no Nordeste, 23 (8,65\%) no Centro-Oeste, $30(11,28 \%)$ no Sudeste e $60(22,55 \%)$ no Sul. As demais 22 localidades $(8,27 \%$ do total), indicadas em vermelho na referida figura, não puderam ser tratadas por apresentarem muitas falhas nas séries temporais. De acordo com Pickering et al. (1994), podem ter ocorrido os seguintes fatores que levaram a essas falhas: medidas não realizadas devido a quebra de equipamento, eventual ausência do responsável pela medição, erros no formato, dados eliminados devido ao erro de coleta, dentre outros.

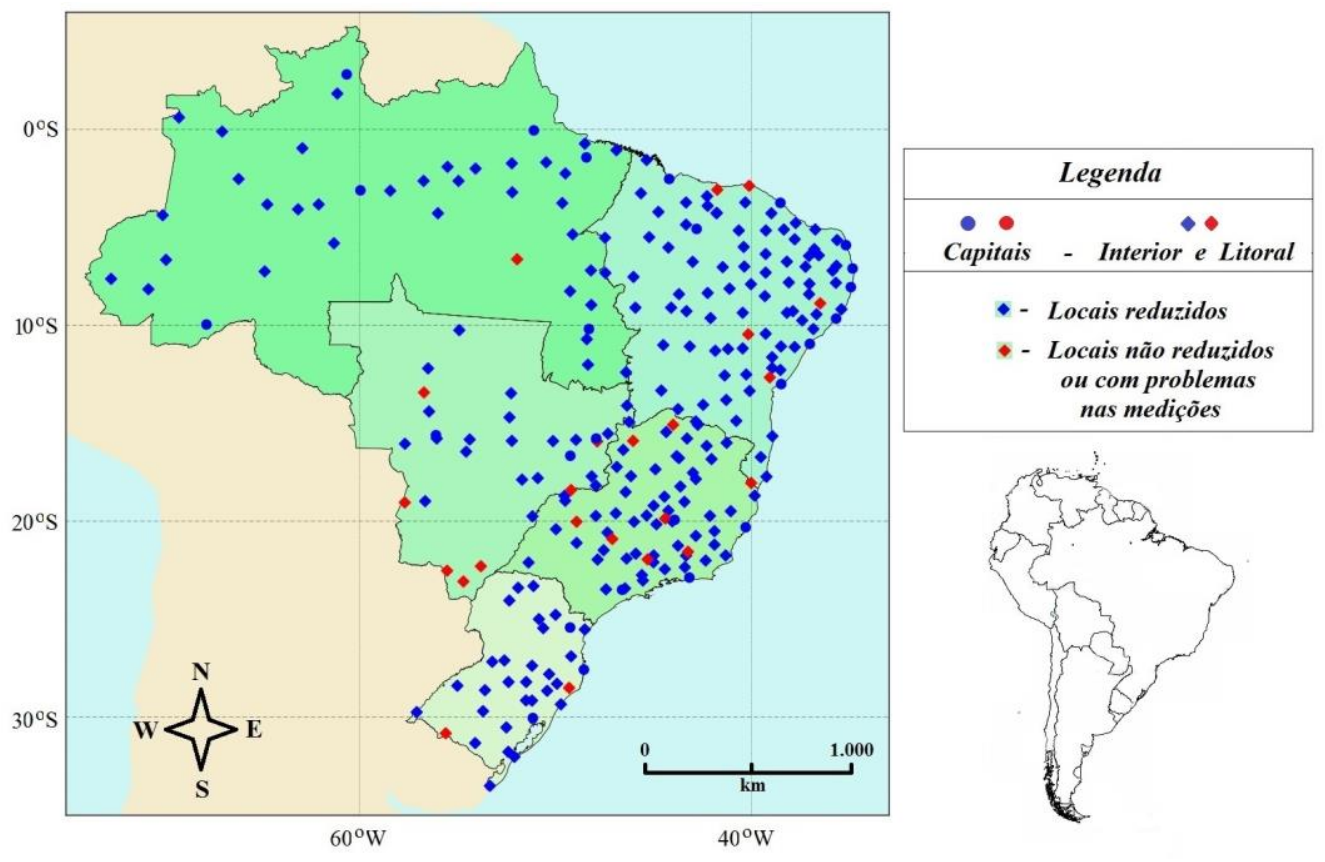

Figura 1 - Distribuição geográfica das estações medidoras pertencentes ao INMET nas regiões políticas do Brasil. 
Durante o processo de organização das séries temporais, foram identificadas falhas nos dados medidos de algumas séries temporais. Em alguns casos, meses e até mesmo anos, não possuíam medições, o que acarretou um corte no período da série a ser reduzida. Neste sentido, é importante salientar que estas falhas podem comprometer seriamente os resultados de muitas pesquisas baseadas em pressupostos corretos e elaborados com grande sofisticação matemática.

As ocorrências de falhas nas medições de uma determinada série foram corrigidas por meio da média com grau três, isto é, calculando a média dos três dias anteriores ou posteriores, se os mesmos também não estivessem com esses erros. Para os períodos com falhas maiores que três dias, optou-se por calcular a média entre os três mesmos meses dos três anos anteriores ou posteriores, conforme cada caso específico. No caso de falhas maiores que três anos, optou-se por eliminar os dados anteriores a essas falhas, restando uma série de período menor que a original, porém com maior consistência nos dados a serem tratados estatisticamente.

Seguindo os mesmos procedimentos de Back (2001) e Groppo et al. (2005), todos dados das localidades informadas na Figura 1 foram organizados, tratados e reduzidos usando planilhas do aplicativo Microsoft Office Excel. Esses procedimentos possibilitaram realizar diferentes tipos de cálculos, particularmente visando correções de eventuais faltas de dados, geração de gráficos, análises do comportamento da variabilidade e da eventual ocorrência de uma tendência nos parâmetros de interesse, além da realização de análises estatísticas acuradas que serão tratadas a seguir.

\subsection{ANÁLISES ESTATÍSTICAS}

Cada série temporal foi tratada pelo teste sequencial de Mann-Kendall $(\mathrm{M}-\mathrm{K})$, proposto inicialmente por Sneyers (1975). Trata-se de um teste não paramétrico no qual, na hipótese de estabilidade de uma série, os valores devem ser independentes e a distribuição de probabilidade deve permanecer sempre a mesma (série aleatória simples) (PINHEIRO et al., 2013).

Considerando uma série $Y_{i}$ de $N$ termos $(1 \leq i \leq N)$ a ser analisada, 0 procedimento consiste em realizar a soma $t_{n}=\sum_{i=1}^{N} m_{i}$ do número de termos $m_{i}$ da série, relativo ao valor $Y_{i}$ cujos termos precedentes $(j<i)$ são inferiores ao mesmo $\left(Y_{j}<Y_{i}\right)$. Para uma série com grande número de termos $(N)$, sob a hipótese nula $\left(H_{0}\right)$ de ausência de tendência, $t_{n}$ apresentará uma distribuição normal com média e variância dada por: $E\left(t_{n}\right)=\frac{N(N-1)}{4} \mathrm{e}$ $\operatorname{Var}\left(t_{n}\right)=\frac{N(N-1)(2 N+5)}{72}$. Utilizando um teste bilateral e estando a significância estatística de $t_{n}$ para a hipótese nula, esta pode ser rejeitada para grandes valores da estatística $U\left(t_{n}\right)$, fornecida pela equação: 


$$
U\left(t_{n}\right)=\frac{\left(t_{n}-E\left(t_{n}\right)\right)}{\sqrt{\operatorname{Var}\left(t_{n}\right)}}
$$

Por meio de uma tabela de distribuição normal padronizada, o valor da probabilidade $\alpha_{1}$ é calculado por: $\alpha_{1}=\operatorname{prob}\left(|U|>\left|U\left(t_{n}\right)\right|\right)$. Sendo $\alpha_{0}$ o nível de significância do teste (geralmente $\alpha_{0}=0,05$ ), a hipótese nula ( $H_{0}$ ) é aceita se $\alpha_{1}>\alpha_{0}$. Caso a hipótese seja rejeitada, existirá uma tendência significativa, sendo que o sinal de $U\left(t_{n}\right)$ indica se a tendência é crescente $\left(U\left(t_{n}\right)>0\right)$ ou decrescente $\left(U\left(t_{n}\right)<0\right)$.

Em sua versão sequencial, a equação $U\left(t_{n}\right)$ é calculada no sentido direto da série, isto é, partindo do valor $i=1$ até $i=N$. Aplicando o mesmo princípio, porém partindo do valor $i=N$ até $i=1$, gera-se a estatística inversa $U^{*}\left(t_{n}\right)$. A intersecção das duas curvas estatísticas, $U\left(t_{n}\right)$ e $U^{*}\left(t_{n}\right)$, corresponde ao ponto aproximado de mudança da tendência procurada. Entretanto, esse procedimento é considerado significativo se o referido ponto de intersecção ocorrer dentro dos intervalos bilaterais $-1,65$ a 1,65 e $-1,96$ a 1,96 correspondentes a $\alpha_{0}=0,10$ (em $10 \%$ ) e $\alpha_{0}=0,05$ (em 5\%), respectivamente (GROPPO et al., 2005; PENEREIRO et al., 2016).

$\mathrm{Na}$ sequência, cada série temporal foi submetida ao teste de homogeneidade de Pettitt (PETT), que se trata de outro método estatístico não paramétrico (PETTITT, 1979; MORAES et al., 1995). Este procedimento utiliza uma versão do teste de Mann-Whitney (FREUND, 2006), no qual se verifica se duas amostras $Y_{1}, Y_{2}, \ldots, Y_{t}$ e $Y_{t+1}, Y_{t+2}, \ldots, Y_{T}$ pertencem à mesma população. Para tanto, é calculada a estatística $u_{t, T}$ por meio de uma contagem do número de vezes que um membro da primeira amostra é maior que um membro da segunda amostra, de acordo com a equação:

$$
u_{t, T}=u_{t-1, T}+\sum_{j=1}^{T} \operatorname{sgn}\left(Y_{i}-Y_{j}\right) ; \quad \text { para } t=2, \ldots ., T
$$

em que: $\operatorname{sgn}\left(Y_{i}-Y_{j}\right)=1$ para $Y_{i}>Y_{j} ; \operatorname{sgn}\left(Y_{i}-Y_{j}\right)=0$ para $Y_{i}=Y_{j}$ e $\operatorname{sgn}\left(Y_{i}-Y_{j}\right)=-1$ para $Y_{i}<Y_{j}$.

Neste teste, obteve-se a estatística $K(t)$ por meio do máximo valor absoluto de $u_{t, T}$. Essa estatística localiza o ponto em que houve uma mudança brusca de uma série temporal e sua significância pode ser avaliada por meio da relação:

$$
p \cong 2 \cdot e^{\left(\frac{-6 \cdot K(t)^{2}}{T^{3}-T^{2}}\right)}
$$


O ponto de mudança é o valor de $t$ onde ocorre o máximo (ou mínimo) de $K(t)$. A equação anterior permite inferir o valor crítico $\left(K_{\text {crit. }}\right)$ por meio da expressão:

$$
K_{\text {crit. }}= \pm \sqrt{\frac{-\ln (p / 2) \cdot\left(T^{3}+T^{2}\right)}{6}}
$$

Para todos os cálculos envolvendo esse teste, adotaram-se os níveis de significância da mudança em $\pm 5 \%$ a $\pm 10 \%$ usando o valor de $K_{\text {crit. }}$ da série trabalhada.

De acordo com a OMM, em sua Nota Técnica $n^{\circ}$. 81, esses são testes recomendados para análises de variabilidades e aferição de tendência (THOM, 1971). Segundo Sansigolo e Nery (2000), os dois testes não paramétricos descritos acima são os melhores procedimentos de análises em séries temporais, visto que possuem um maior embasamento estatístico para modelos teóricos de descrições climáticas. Como comentado por Penereiro et al. (2016), torna-se significativo utilizar os testes de Pettitt e Mann-Kendall combinados, isto é, realizando análises gráficas e numéricas em conjunto para que se possa identificar e localizar quando uma possível tendência na série temporal passou a existir.

\section{RESULTADOS E DISCUSSÃO}

Devido à grande quantidade de informações numéricas obtidas, a seguir são apresentados alguns resultados estatísticos em forma de gráficos. Adicionalmente, serão apresentadas tabelas e mapas contendo as distribuições de tendências inferidas para as quatro variáveis climáticas abordadas no presente levantamento.

\subsection{ANÁLISES DOS TESTES ESTATÍSTICOS}

Para exemplificar as análises dos testes M-K e PETT, algumas formas gráficas desses testes são mostradas nas Figuras 2 e 3 . O teste $M-K$ está representado em linhas pretas. As linhas horizontais tracejadas e pontilhadas referem-se os intervalos de confiança $\pm 5 \%$ a $\pm 10 \%$, sendo a curva estatística $U\left(t_{n}\right)$ representada em linha contínua e a $U^{*}\left(t_{n}\right)$ em linha tracejada. De no teste PETT, exposto em cor vermelha, os níveis de confiança de $\pm 5 \%$ a $\pm 10 \%$ estão evidenciadas em linhas horizontais tracejadas e pontilhadas, respectivamente, a curva estatística $K(t)$ é mostrada em linha respectivamente, a curva estatística é mostrada em linha contínua.

Com o intuito de estabelecer um critério que expressasse os resultados desses dois testes não paramétricos, optou-se por utilizar a seguinte convenção: o sinal $(-)(-)$ para uma tendência negativa confirmada entre $5 \%$ e $10 \%$ dos intervalos de confianças bilaterais e o sinal (-) se for acima de $10 \%$ do nível do intervalo de confiança. De maneira análoga, usou-se os sinais $(+)(+)$ e $(+)$ para tendência positiva confirmada, respectivamente. Em situações onde não houve 
condições de confirmar tendência, um sinal (?) foi adotado para o teste empregado à série temporal.

$\mathrm{Na}$ Figura 2 estão mostrados os gráficos relativos às análises não paramétricas para os dados de T-Méd. e T-Mín., respectivamente, nas cidades de Curitiba (PR) e Juiz de Fora (MG).

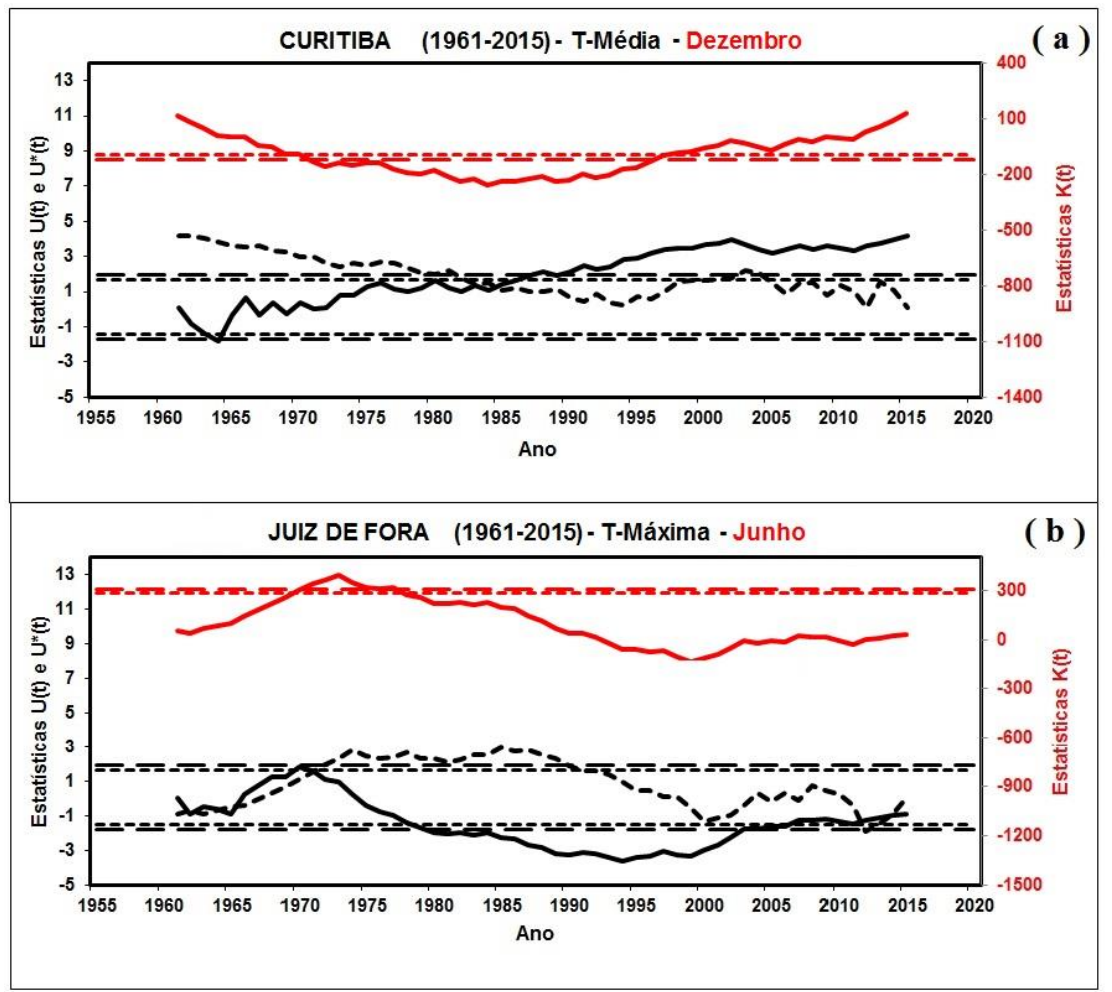

Figura 2 - Resultados do teste M-K (inferior) e PETT (superior) para as medidas de: (a) T-Méd. em dezembro de Curitiba (PR) e (b) T-Máx. em junho de Juiz de Fora (MG).

A variável climática T-Méd. de Curitiba, com dados no mês de dezembro, entre 1961 e 2015 mostrados na Figura 2a, revelou tendência de aumento a partir de 1984. Isso se justifica porque ocorreu o cruzamento das curvas $U\left(t_{n}\right)$ e $U^{*}\left(t_{n}\right)$ do teste M-K entre os intervalos de confianças em 1984. Não obstante, o ponto de mudança brusca de $K(t)$ no teste PETT cruzou os limites críticos estabelecidos de $5 \%$ e $10 \%$ com o mínimo inferido em 1985 . Em que pese essas datas estarem defasadas em apenas um ano uma da outra, optou-se por confirmar que existe tendência positiva nessa série temporal a partir de dezembro de 1985. A data inferida pelo teste de PETT foi considerada por ser um método estatístico melhor elaborado para a definição de data de ocorrência de tendência (PENEREIRO et al., 2016). A data observada está de acordo como trabalho de Silva et al. (2015), no qual constatou que a porcentagem de dias e noites quentes no Estado do Paraná, no qual Curitiba é a capital, aumentou consideravelmente a uma taxa de 0,1 a 0,4 \%/ano entre 1976 e 2010. Os autores ressaltam que as médias anuais das temperaturas mínimas e máximas 
indicam uma elevação em quase todo o Paraná em torno de $+0,02^{\circ} \mathrm{C} /$ ano no mesmo período.

De maneira análoga, para variável T-Máx. de Juiz de Fora em junho, no período de 1961 a 2015, os testes M-K e PETT (Figura 2b) confirmaram o registro de tendência negativa a partir de 1973. Isso se deve porque, como se verifica no gráfico inferior da figura, ocorreu o cruzamento das curvas estatísticas $U\left(t_{n}\right)$ e $U^{*}\left(t_{n}\right)$ entre os intervalos de confianças em 1972, enquanto que curva $K(t)$, mostrada no gráfico superior da mesma figura, cruzou os dois níveis de confiança com o máximo inferido em 1973. Como no caso anterior, em Curitiba, as datas estão defasadas em um ano, o que levou a confirmar que existe tendência negativa nessa série temporal a partir de junho de 1973.

Os resultados obtidos corroboram com o trabalho de Ávila et al. (2014), que demonstrou uma tendência significativa de redução das temperaturas máximas em escala sazonal no período de 1961 a 2009, com taxas de até $-0,5^{\circ} \mathrm{C}$ por década, no município de Juiz de Fora. Os autores ressaltam que esta mesma estação climatológica também apresentou tendência de redução das temperaturas mínimas, para o mês de janeiro.

A Figura 3 revela os gráficos dos comportamentos medidos para as variáveis climáticas de T-Mín. e Prec. nas cidades de Brasília (DF) e Conceição do Araguaia (PA), respectivamente.

Para as medidas de T-Mín. durante o mês de junho em Brasília (Figura 3a), nenhuma tendência pode ser atribuída no período de 1961 a 2015, pois em nenhum momento ocorreu o cruzamento das curvas estatísticas do teste $\mathrm{M}-\mathrm{K}$ entre os intervalos de confianças, apesar da curva do teste PETT ter cruzado os dois níveis de confiança com o máximo registrado em junho de 1986 . Sendo assim, constatou-se a ausência de tendência na série temporal de T-Mín. para os dados observados na capital do país.

No caso da precipitação (Prec.) registrada em Conceição do Araguaia, com dados no mês de dezembro, entre 1961 e 2015 (Figura 3b), nenhuma tendência foi confirmada. Isso se deve porque ao aplicar os testes estatísticos ocorreram vários cruzamentos das curvas $U\left(t_{n}\right)$ e $U^{*}\left(t_{n}\right)$ entre os intervalos de confiança e, além disso, a curva $K(t)$, mostrada no gráfico superior da figura, em nenhum momento cruzou um dos níveis de confiança de $\pm 5 \%$ e $\pm 10 \%$. Em decorrência disso ficou descartada a existência de tendência na Prec. para essa localidade. 


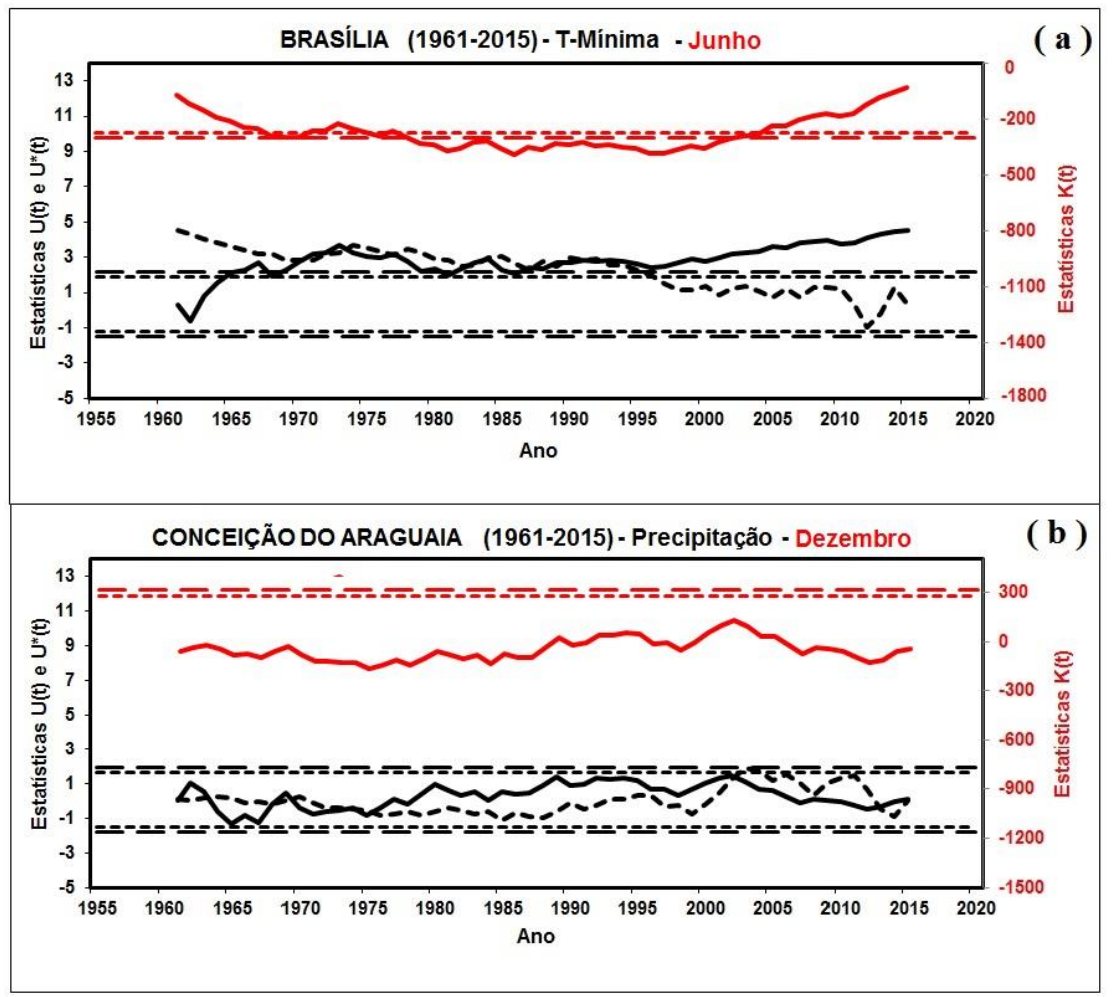

Figura 3 - O mesmo que a Figura 2, porém para as medidas de: (a) T-Mín. de Brasília (DF), em junho, e (b) Prec. de Conceição do Araguaia (PA), em dezembro.

Por meio das análises envolvendo as formas gráficas dos testes $M-K$ e PETT, como mostrados nos exemplos anteriores, todos os dados provenientes das 243 estações do INMET tratadas neste estudo foram organizados e tabelados. As Tabelas 1 e 2 apresentam, respectivamente para os meses de junho e dezembro, um resumo dos resultados de tais testes para as localidades abordadas em cada região política do Brasil. Nessas tabelas foi adotada a convenção de sinais discutida anteriormente, visando identificar as análises com resultados de tendência negativa $(-)$, positiva (+) ou ausência (?).

Tabela 1 - Quantidade de cidades estudadas, em cada região política do Brasil, classificadas quanto à tendência climática identificada pelos testes estatísticos $\mathrm{M}-\mathrm{K}$ e PETT aplicados em cada variável climática no mês de junho.

\begin{tabular}{c|ccc|c|c|c|c|cc|c|c|c|c}
\hline Região Política & \multicolumn{3}{|c|}{ T-Mín. } & \multicolumn{3}{c|}{ T-Máx. } & \multicolumn{3}{c|}{ T-Méd. } & \multicolumn{3}{c}{ Prec. } \\
\hline & $\mathbf{( - )}$ & $\mathbf{( + )}$ & $\mathbf{( ? )}$ & $\mathbf{( - )}$ & $\mathbf{( + )}$ & $\mathbf{( ? )}$ & $\mathbf{( - )}$ & $\mathbf{( + )}$ & $\mathbf{( ? )}$ & $\mathbf{( - )}$ & $(+)$ & $(\mathbf{?})$ \\
\hline Norte & 0 & 16 & 24 & 0 & 22 & 18 & 0 & 20 & 20 & 0 & 2 & 38 \\
Nordeste & 8 & 26 & 56 & 1 & 30 & 58 & 4 & 22 & 64 & 5 & 5 & 80 \\
Centro-Oeste & 0 & 6 & 17 & 0 & 8 & 15 & 0 & 8 & 15 & 0 & 2 & 21 \\
Sudeste & 1 & 4 & 25 & 1 & 4 & 25 & 1 & 4 & 25 & 1 & 2 & 27 \\
Sul & 1 & 14 & 45 & 5 & 23 & 33 & 1 & 21 & 38 & 0 & 2 & 58 \\
TOTAL & $\mathbf{1 0}$ & $\mathbf{6 6}$ & $\mathbf{1 6 7}$ & $\mathbf{7}$ & $\mathbf{8 7}$ & $\mathbf{1 4 9}$ & $\mathbf{6}$ & $\mathbf{7 5}$ & $\mathbf{1 6 2}$ & $\mathbf{6}$ & $\mathbf{1 3}$ & $\mathbf{2 2 4}$ \\
\hline
\end{tabular}


Tabela 2 - Idem à tabela anterior, porém aplicados para variáveis climáticas no mês de dezembro.

\begin{tabular}{c|ccc|c|c|c|c|cc|c|c|c|c}
\hline Região Política & \multicolumn{3}{|c|}{ T-Mín. } & \multicolumn{3}{c|}{ T-Máx. } & \multicolumn{3}{c|}{ T-Méd. } & \multicolumn{3}{c}{ Prec. } \\
\hline & $\mathbf{( - )}$ & $\mathbf{( + )}$ & $\mathbf{( ? )}$ & $\mathbf{( - )}$ & $\mathbf{( + )}$ & $\mathbf{( ? )}$ & $\mathbf{( - )}$ & $\mathbf{( + )}$ & $\mathbf{( ? )}$ & $\mathbf{( - )}$ & $(+)$ & $(\mathbf{?})$ \\
\hline Norte & 0 & 21 & 19 & 1 & 20 & 19 & 0 & 27 & 13 & 1 & 1 & 38 \\
Nordeste & 19 & 20 & 52 & 1 & 15 & 75 & 4 & 16 & 69 & 3 & 0 & 86 \\
Centro-Oeste & 1 & 11 & 11 & 0 & 7 & 16 & 0 & 13 & 10 & 1 & 0 & 22 \\
Sudeste & 0 & 7 & 23 & 2 & 6 & 22 & 1 & 7 & 22 & 2 & 1 & 28 \\
Sul & 2 & 24 & 33 & 1 & 20 & 38 & 1 & 23 & 36 & 1 & 1 & 58 \\
TOTAL & $\mathbf{2 2}$ & $\mathbf{8 3}$ & $\mathbf{1 3 8}$ & $\mathbf{5}$ & $\mathbf{6 8}$ & $\mathbf{1 7 0}$ & $\mathbf{6}$ & $\mathbf{8 6}$ & $\mathbf{1 5 1}$ & $\mathbf{8}$ & $\mathbf{3}$ & $\mathbf{2 3 3}$ \\
\hline
\end{tabular}

Observa-se que, tanto para as análises do mês de junho como do mês de dezembro, o total de localidades que não apresentou tendências foi sempre maior que $50 \%$ do total de localidades estudadas (243). Destacam-se as análises de precipitação, que no mês de junho foi de $92,8 \%$ de localidades sem tendência e no mês de dezembro foi de $95,8 \%$. Sendo assim, grandes variações regionais e sazonais permanecem, mas as tendências em muitas regiões não são estatisticamente significativas.

No entanto, em análise regional, observa-se que no mês de junho para a região Norte o número de localidades com tendências de aumento na temperatura máxima e na temperatura média foi maior que o número de localidades sem tendência. O mesmo foi observado nas análises do mês de dezembro para a região Norte, porém incluindo a temperatura mínima para esta mesma região e também para a região Centro-Oeste.

Esses resultados corroboram com o trabalho de Salviano et al. (2016), no qual observaram que a precipitação não apresenta tendências significativas em mais de $70 \%$ do território brasileiro em todos os meses entre os anos de $1961 \mathrm{e}$ 2011. Além disso, o Quarto Relatório do IPCC (AR4/IPCC, 2007) ressalta que muitas análises indicam que a variabilidade temporal da chuva, em escala global, durante a segunda metade do século XX é dominada por variações na escala de tempo interanual e interdecadal e que as estimativas de tendência são espacialmente incoerentes (IPCC, 2007).

Dentre as localidades que apresentaram tendências neste estudo, tanto em junho como em dezembro, em todas as regiões do Brasil e em todas as variáveis meteorológicas estudadas, o número de localidades com tendência de diminuição foi sempre menor que o número de localidades com tendência de aumento.

Esses resultados ressaltam a dificuldade em se apontar a ocorrência de tendência climática no Brasil. Observa-se que os casos de ocorrência de tendência são isolados, levantando a dificuldade em dissociar essas alterações às variações naturais do clima.

Como foram tratadas um total de 1944 séries temporais neste levantamento, a quantidade de informações numéricas é muito grande. Neste sentido, optou-se por elaborar mapas das distribuições espaciais de tendências das variáveis climáticas em território brasileiro, como os apresentados nas Figuras 4 a 7. Cada mapa corresponde a uma determinada grandeza climática trabalhada, sendo possível, por meio de uma análise visual, identificar os locais onde se detectaram tendências crescentes (+) e decrescentes (-). 


\subsection{MAPAS DAS DISTRIBUIÇÕES DE TENDÊNCIAS}

\subsection{A. PARA A TEMPERATURA MÍNIMA (T-MÍN.)}

Os mapas da Figura 4 revelam a distribuição espacial da T-Mín. Destacam-se na Figura 4a, como indicam os dados numéricos da Tabela 1 para o mês de junho, 66 locais com registros de tendências de aumento dessa variável, o que corresponde a $27,16 \%$ das localidades analisadas. Neste período do ano, a região Nordeste foi a que apresentou o maior número de casos (26), seguida pelas regiões Norte (16), Sudeste (14), Centro-Oeste (6) e Sul (4).

Ressalta-se que como as análises foram realizadas em períodos diferenciados, que dependeram da disponibilidade dos dados, não se pode concluir que as tendências observadas são devido a alterações climáticas de ordem global. É importante observar que as tendências estão distribuídas no país de forma não uniforme, podendo ser representativas da variabilidade natural do clima.

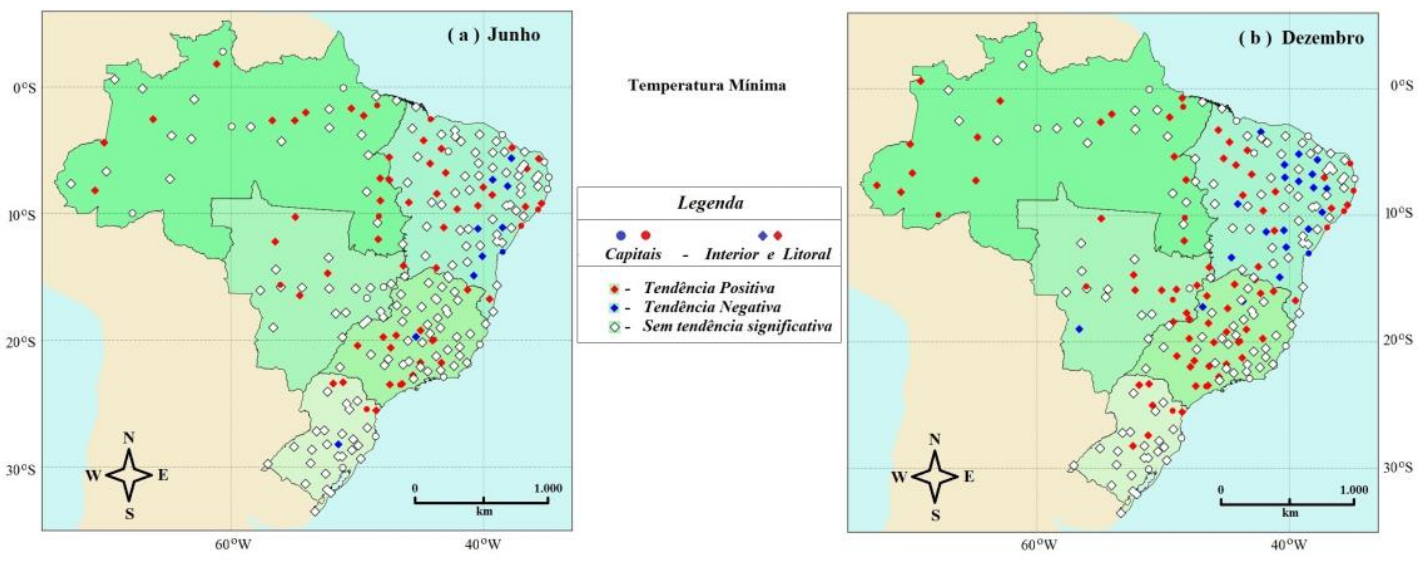

Figura 4 - Mapas das tendências climáticas para a T-Mín. nas 243 cidades brasileiras avaliadas em: (a) Junho e (b) Dezembro.

As tendências positivas observadas na região Sul (Figura 4a e 4b) encontram-se em sua maioria na porção norte dessa região, enquanto que para a região política do Centro-Oeste as tendências observadas estão localizadas ao norte e na porção central. Há dois grandes grupos de localidades sem tendências observadas no mês de junho: um na região central do país, que inclui a porção leste da região Centro-Oeste e a porção norte da região Sudeste, a outra localiza-se nas porções sul e leste da região Sul do país.

Tendências negativas foram observadas em 10 localidades, correspondendo a $4,12 \%$ dos locais analisados. A região Nordeste foi a que apresentou o maior número de casos (8), seguida pelas Sudeste e Sul (1 cada). As tendências negativas se encontram na faixa leste da região Nordeste. As regiões Centro-Oeste e Norte não acusaram tendências. Em 167 localidades analisadas, o que equivale a $68,72 \%$ de todo o levantamento, não ocorreu a comprovação de tendência na T-Mín. (Tabela 1), sendo a região Nordeste a que apresentou o maior número de casos (56), seguida pelas regiões Sul (45), Sudeste (25), Norte (24) e Centro-Oeste (17). 
Para o mês de dezembro, o mapa da Figura 4b revela a ocorrência de 83 locais com tendências de aumento da T-Mín., o que corresponde a 34,16\% das localidades analisadas. Para esse período, a região Sudeste foi a que apresentou o maior número de casos (24), seguida pelas regiões Norte (21), Nordeste (20), Centro-Oeste (11) e Sul (7). Quanto às tendências negativas, ocorreram 22 registros em localidades, representando $9,05 \%$ dos locais avaliados. A região Nordeste foi a que apresentou o maior número de casos (19), seguida pelas regiões Sudeste (2) e Centro-Oeste (1). As regiões Sul e Norte não acusaram tendências.

No total de 138 locais analisadas, o que equivale a 56,79\% das localidades, não ocorreu a comprovação de tendência na T-Mín. (Tabela 2), sendo novamente a região Nordeste a que apresentou o maior número de casos (52), seguida pelas regiões Sul (33), Sudeste (23), Norte (19) e Centro-Oeste (11).

Observa-se que a porcentagem de tendências para T-Mín. detectadas em junho e dezembro (Tabelas 1 e 2), seja positiva ou negativa, localizam-se no interior do país, principalmente nas regiões Nordeste e Sudeste (Figura 4). Constata-se ainda que ausências de tendências na T-Mín. foram identificadas de maneira espalhada por todo o Brasil, particularmente nas proximidades das regiões costeiras (Figura 4). Conforme discutido anteriormente, a quantidade de tendências observadas, a não uniformidade, e o comprimento das séries históricas analisadas contribuem para o levantamento da hipótese de uma grande variabilidade climática em oposição à tendência climática generalizada.

\subsection{B. PARA A TEMPERATURA MÁXIMA (T-MÁX.)}

Quanto à distribuição espacial da variável T-Máx., mostrada na Figura 5, para o mês de junho (Figura 5a) foram encontrados 87 locais (35,80\%) com evidências de tendência positiva, sendo a região Nordeste a que apresentou 0 maior número de casos (30), seguida das regiões Sudeste (23) e Norte (22), depois a Centro-Oeste (8) e Sul (4). Foram poucas as localidades onde se registrou tendência negativa na $T$-Máx., destacando apenas sete casos $(2,88 \%)$, sendo cinco casos na região Sudeste e apenas um caso nas regiões Nordeste e Sul. Nenhuma tendência negativa foi registrada nas regiões Norte e CentroOeste. Identificou-se 149 localidades (61,32\%) que não acusaram indícios de tendências para essa variável climática (Tabela 1), destacando-se a região Nordeste com 58 casos, o centro-sul da região Sul com 33 locais, o litoral e interior da região Sudeste com 25 casos, e as regiões Norte e Centro-Oeste com 18 e 15 locais, respectivamente. 

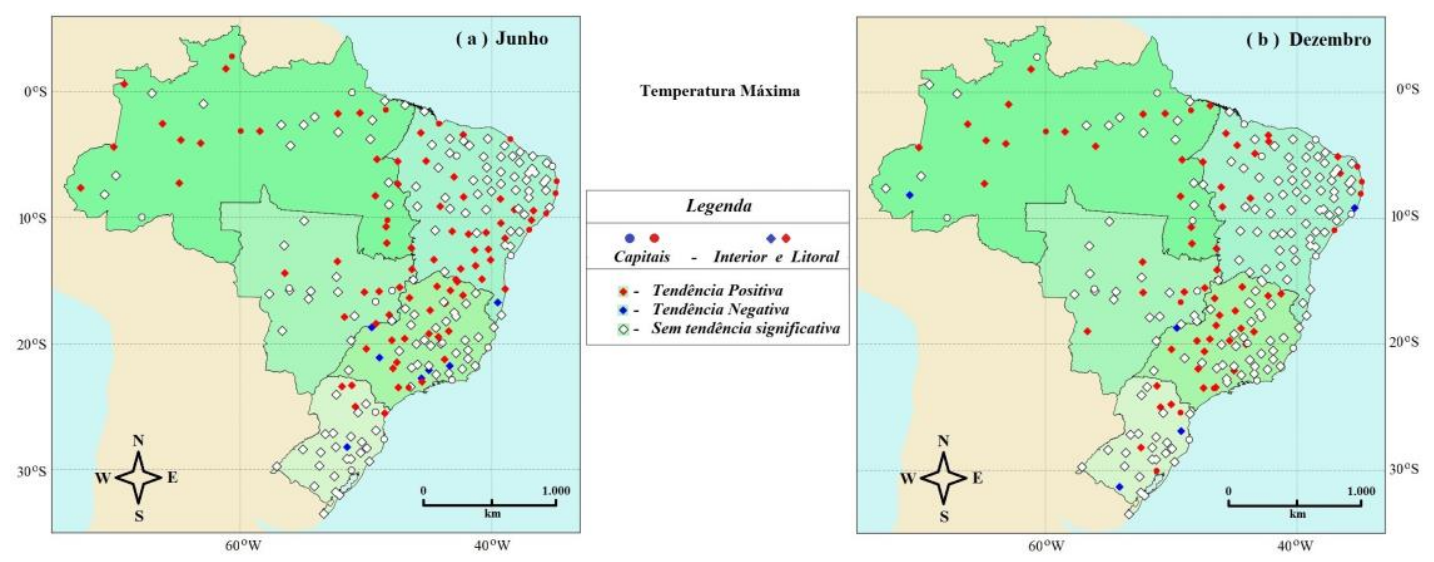

Figura 5 - Mapas das tendências climáticas para a T-Máx. detectadas em localidades brasileiras em: (a) Junho e (b) Dezembro.

Quanto ao mês de dezembro, o mapa da Figura $5 b$ mostra as 68 localidades que acusaram tendências de aumento da T-Máx., o que equivale a $27,98 \%$ dos locais avaliados. Para esse período, as regiões Norte e Sudeste foram as que apresentaram o maior número de casos (20 cada), seguida pelas regiões Nordeste (15), Centro-Oeste (7) e Sul (6). Tendências negativas foram registradas em apenas cinco localidades, representando $2,06 \%$ dos locais avaliados. A região Sul acusou dois casos, seguida pelas regiões Norte, Sudeste e Nordeste com um local cada. Os locais da região Centro-Oeste não registraram diminuição de tendência na T-Máx. Nenhuma comprovação de tendência para a T-Máx. foi identificada em 170 locais analisados (Tabela 2), o que equivale a $69,96 \%$ de todas as localidades, sendo a região Nordeste a que apresentou o maior número de casos (75), seguida pelas regiões Sul (38), Sudeste (22), Norte (19) e Centro-Oeste (16).

Nos mapas apresentados anteriormente (Figuras 4 e 5 ), constata-se que as variações regionais e sazonais observadas, além das tendências em muitas regiões, não são estatisticamente significativas. De acordo com Sansigolo et al. (1992), as regiões Sul e Sudeste do Brasil têm apresentado um aquecimento sistemático desde o início do século $\mathrm{XX}$, podendo estar associado à crescente urbanização. Conforme relataram Venegas et al. (1996; 1997), o aquecimento desde 1950 acusado na região do Atlântico Sul é um outro fator que pode ter contribuído para o aumento da temperatura nessas regiões do país.

Ao analisar os mapas da Figura 5, verifica-se que a porcentagem de tendências para T-Máx. detectadas em junho e dezembro, seja positiva ou negativa, também se localizam no interior do país, excetuando-se algumas localidades próximas ou no litoral das regiões Norte e Nordeste.

\subsection{PARA A TEMPERATURA MÉDIA (T-MÉD.)}

A Figura 6 mostra a distribuição espacial da variável T-Méd. No caso do mês de junho (Figura 6a) foram encontrados 75 locais (30,86\%) com evidências de tendência positiva. Assim como para a T-Máx., a região Nordeste foi a que apresentou o maior número de casos (22), seguida das regiões Sudeste (21) e Norte (20), depois a Centro-Oeste (8) e Sul (4). Foram registradas poucas 
localidades com tendência negativa na T-Méd., destacando somente seis locais $(2,47 \%)$, sendo quatro casos na região Nordeste e apenas um caso nas regiões Sul e Sudeste. Verificou-se que nenhuma tendência negativa foi registrada nas localidades das regiões Norte e Centro-Oeste. Constatou-se que 162 localidades $(66,67 \%)$ não registraram indícios de tendências na T-Méd. (Tabela 1$)$, sendo a região Nordeste com 64 casos, a região Sul com 38 locais, as regiões Sudeste, Norte e Centro-Oeste com 25, 20 e 15 casos, respectivamente.

Em relação à distribuição de tendências para $T$-Méd. no mês de dezembro, o mapa da Figura $6 \mathrm{~b}$ mostra as 86 localidades que acusaram aumento dessa variável climática, o equivalente a $35,39 \%$ dos locais avaliados. Para esse período, a região Norte foi a que apresentou o maior número de casos (27), seguida pelas regiões Sudeste (23), Nordeste (16), Centro-Oeste (13) e Sul (7). Os registros de tendências negativas foram identificados em seis locais, equivalendo a $2,47 \%$ das localidades avaliadas. Na região Nordeste houve quatro registros de decréscimo da T-Méd., seguida pelas regiões Sul e Sudeste que acusaram apenas um local cada, e as regiões Norte e Centro-Oeste que não acusaram tendências durante o mês de dezembro. Nenhuma inferência de tendência para a T-Méd. foi identificada em 151 localidades analisadas (Tabela 2 ), o que representa $62,14 \%$ de todas as localidades. Neste sentido, a região Nordeste foi a que apresentou o maior número de casos (69), seguida pelas regiões Sul (37), Sudeste (22), Norte (13) e Centro-Oeste (10).

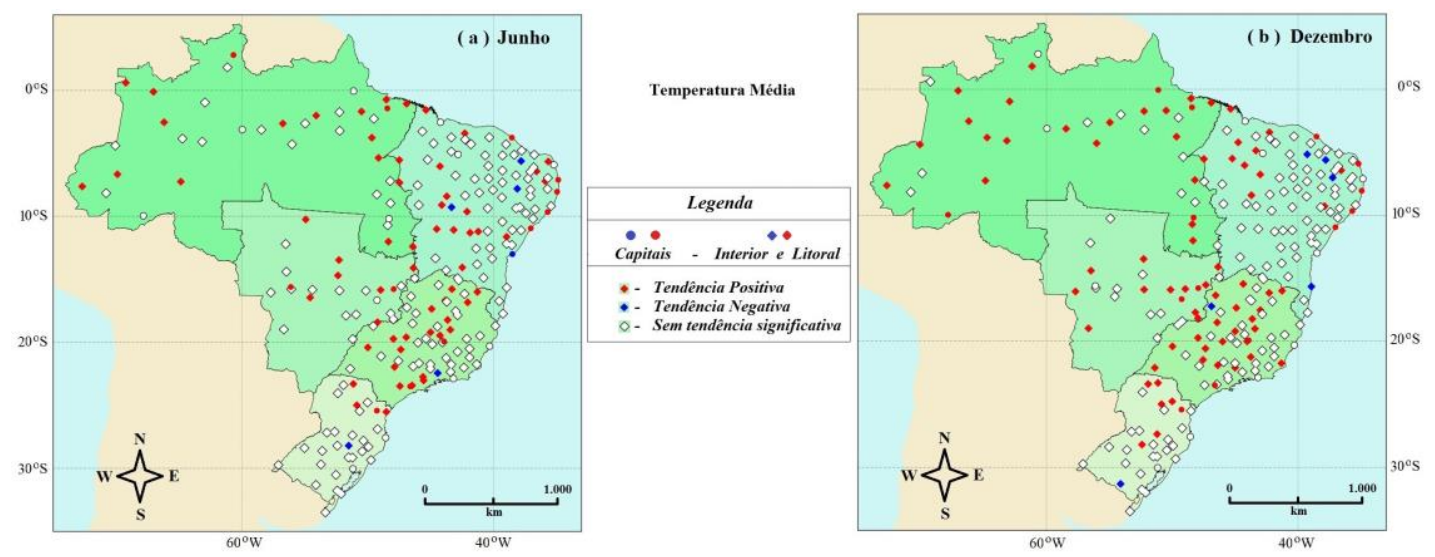

Figura 6 - Idem à figura anterior, porém para as tendências na T-Méd. inferidas em: (a) Junho e (b) Dezembro.

Observa-se por meio dos mapas da Figura 6 que a porcentagem de tendências positivas ou negativas para $T$-Méd. se localizam principalmente nas regiões Norte, Sudeste e Nordeste.

\subsection{PARA A PRECIPITAÇÃO PLUVIOMÉTRICA (PREC.)}

No que se refere à Prec., constatou-se através dos mapas da Figura 7 que esta foi a variável climática que mais acusou ausência de tendência, pois foram registrados 224 locais no mês de junho e 233 locais em dezembro (Tabelas 1 e 2), representando $92,18 \%$ e $95,88 \%$, respectivamente, das localidades tratadas nesse levantamento. Neste contexto, destacam-se tanto para junho como para dezembro, por ordem decrescente do número de 
localidades, a região Nordeste com 80 e 86 locais, acompanhada da região Sudeste, ambos meses com 58 casos, assim como na região Norte, ambos meses com 38 locais, a região Sul, com 27 e 28 locais, e da região Centro-Oeste com 21 e 22 locais, respectivamente.

Aumentos de Prec. para o mês de junho (Figura 7a) foram registrados em 13 localidades $(5,35 \%$ do total), estando o maior número de locais registrados na região Nordeste com cinco casos, seguidas das regiões Norte, Centro-Oeste, Sul e Sudeste com duas localidades cada. As diminuições de chuvas em junho foram detectadas em apenas seis locais $(2,47 \%)$, com cinco casos na região Nordeste e um caso na região Sul. Analisando-se o referido mapa, observa-se ainda que nenhuma localidade das regiões Sudeste, CentroOeste e Norte registrou diminuição na Prec. (Figura 7a).

Os resultados envolvendo a Prec. para o mês de dezembro estão revelados na Figura $7 \mathrm{~b}$. O referido mapa indica que foram detectados aumento de Prec. em apenas três locais (1,23\%), localizadas nas regiões Sudeste, Sul e Norte. Portanto, nenhuma tendência positiva foi registrada nas regiões Nordeste e Centro-Oeste. Analisando-se o referido mapa, verifica-se ainda que as diminuições de Prec. foram detectadas em oito localidades $(3,29 \%)$, com três casos na região Nordeste, dois locais na região Sul e um caso nas regiões Norte, Centro-Oeste e Sudeste.

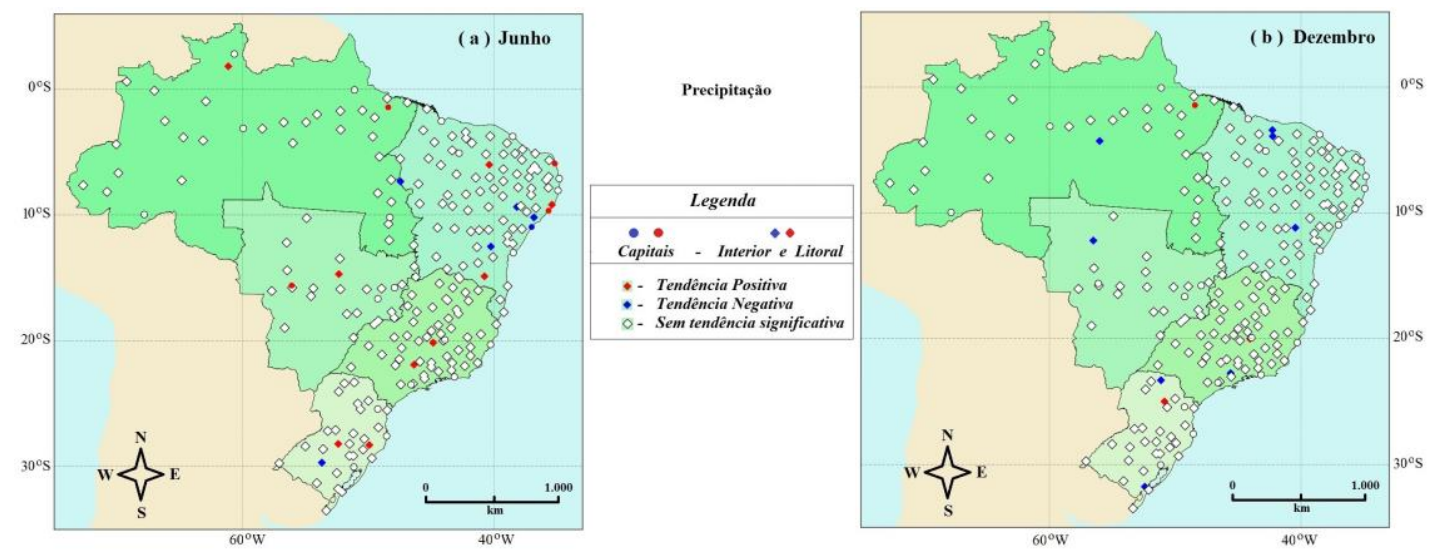

Figura 7 - O mesmo que as três últimas figuras, mas agora para tendências climáticas em Prec. durante: (a) junho e (b) dezembro.

Vale lembrar que os resultados nas tendências de Prec. aqui discutidos não concordam com os encontrados na base de dados contidas no trabalho Alexander et al. (2006), que abordou 2200 estações de precipitação pluvial espalhadas pelo planeta, sendo poucas dessas estações localizadas no Brasil. Como pode ser observado nos mapas da Figura 7, foram poucas as ocorrências de tendências no aumento ou diminuição dos níveis chuva, sendo que as mesmas se encontram espalhadas por localidades de todas as regiões políticas do Brasil.

Os resultados do presente estudo concordam com as análises de Marengo (2007). De acordo com esse autor, as variações de precipitação na Amazônia e no Nordeste apresentam uma variabilidade interanual e em escalas de tempo interdecadal, sendo mais significativas que as ocorrências de tendências. No Sul 
do Brasil, de acordo com o mesmo autor, tendências de aumento na precipitação são observadas desde meados do século $X X$, enquanto que na Amazônia, mesmo com a ocorrência de constantes desmatamentos, não foram observadas tendências significativas nas chuvas. No entanto, no Nordeste as tendências são comumente não estatisticamente significativas (MARENGO, 2007). Além disso, conforme descrito por Marengo (2014), apesar das incertezas relacionadas às tendências da precipitação, há grande confiabilidade no aumento de tendência para a região Sul do Brasil e a Bacia do Prata, mas no leste da Amazônia e o Nordeste haverá redução. As chuvas tendem a diminuir durante o século XXI, sendo as reduções mais intensas no Nordeste e na Amazônia (MARENGO, 2014).

\subsection{FREQUÊNCIAS TEMPORAL DAS TENDÊNCIAS}

Os histogramas apresentados nas Figuras 8 e 9 indicam as frequências temporal das tendências totais (a soma das tendências positivas e negativas) observadas nos meses de junho e dezembro, respectivamente. Em cada uma dessas figuras, a Prec. está representada em azul, enquanto que a T-Mín. está em cinza, a T-Máx. em vermelho e a T-Méd. em verde.

Ao analisar a Figura 8, relativa ao mês de junho, observa-se que as maiores quantidades de tendências foram registradas nas temperaturas do ar e precipitação na primeira década do século XXI, com destaque para os aumentos de temperaturas.

A figura $8 a$, relativa às análises para o mês de junho na região Norte, indica que com o passar das décadas houve um aumento na frequência de tendências detectadas para T-Máx. e T-Mín., sendo o pico durante os anos 2000, com 9 tendências observadas para T-Máx. e 8 para T-Mín. A T-Méd. também teve seu pico (9) de frequências detectadas nesse período. Na região Nordeste (Figura 8b) as quantidades de tendências observadas são, em geral, em maior número que na região Norte. Constata-se que a maiorias das tendências observadas tiveram início nos anos 2000, com exceção da Prec., que ocorreu com maior frequência a partir da década de 1990. A região Sul (Figura 8c) apresenta poucas tendências observadas. Para a região Sudeste (Figura 8d) ressalta-se a T-Máx. e a T-Méd. com 19 e 16 tendências, respectivamente, que se iniciam na década de 1990. Na região Centro-Oeste (Figura 8e) a T-Méd. e a $T$-Mín. tiveram a maior frequência de tendências detectadas iniciando na década de 2000, enquanto que a T-Máx. teve seu pico de frequência para tendências na década de 1990.

Ressalta-se que o número de locais que apresentaram tendências é menor que $50 \%$ do total de localidades analisadas. Esse resultado esclarece que as tendências climáticas observadas possivelmente estão relacionadas a mudanças regionais, como urbanização, e não caracterizada apenas pelas mudanças climáticas de ordem global. 


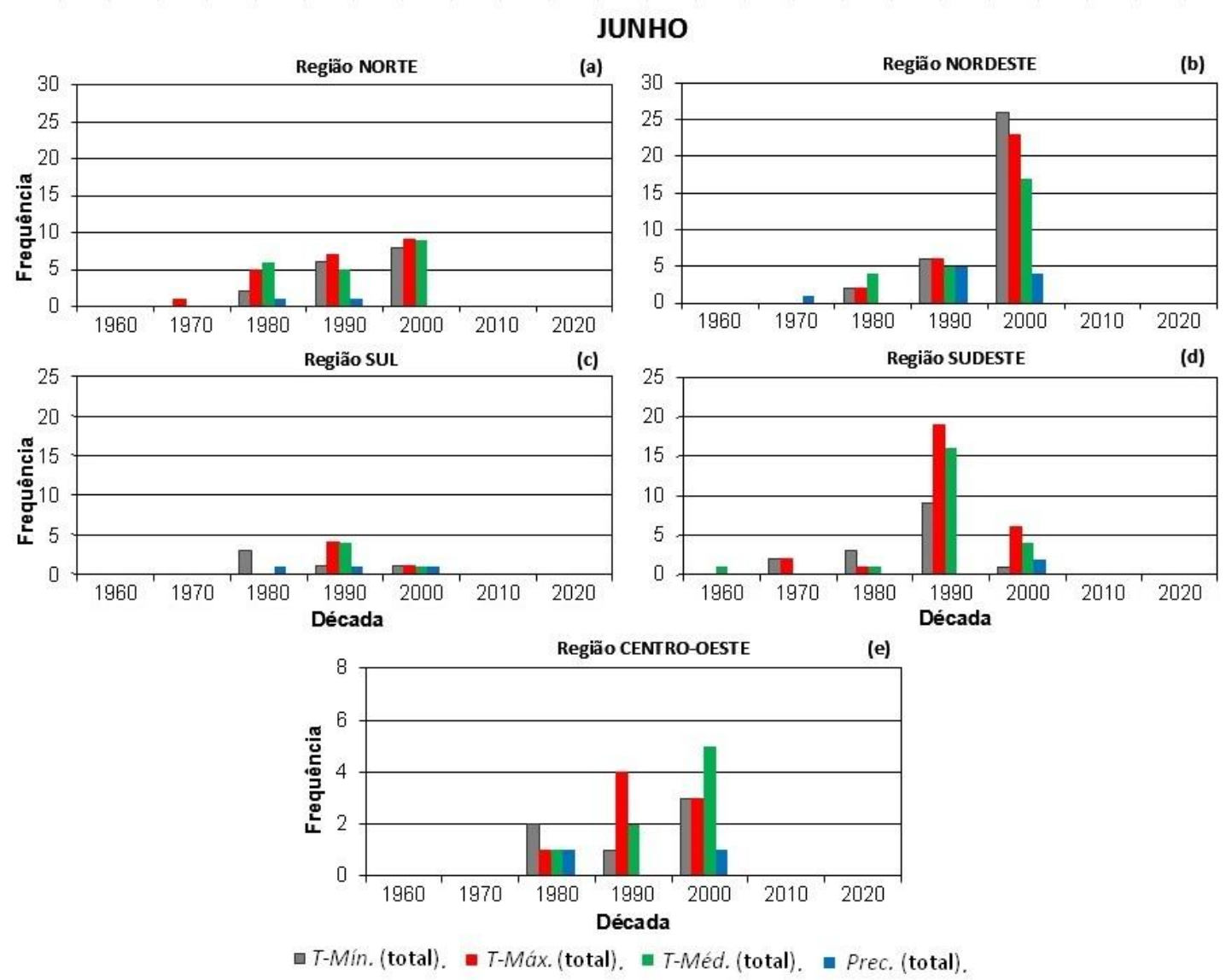

Figura 8 - Histograma com as contagens de tendências em relação às décadas em que as mesmas ocorreram para as quatro variáveis climáticas tratadas no mês de junho.

Analogamente, na Figura 9 tem-se o histograma relacionado às frequências temporárias das tendências relacionadas ao mês de dezembro. Observa-se que as maiores quantidades de tendências foram registradas no final do século $X X$, portanto num período diferente daquele registrado $e$ discutido anteriormente para o mês de junho.

Mais uma vez o destaque está nos aumentos de temperaturas do ar. $\mathrm{Na}$ região Norte (Figura 9a) as temperaturas tiveram seu pico de frequência de tendências detectadas na década de 1990: T-Méd. com 18 tendências e T-Máx. e T-Mín. com 13 tendências cada. Na região Nordeste (Figura 9b) a T-Mín. exibe dois picos de frequência: um na década de 1990 (18 casos) e o outro em 2000 (21 casos). Por meio dessa figura, percebe-se que número de detecções de tendências na T-Mín. foi em geral maior do que na T-Máx. e T-Méd. Na região Sul (Figura 9c), da mesma forma que nas análises do mês de junho, apresenta poucas tendências observadas. Para a região Sudeste (Figura 9d) os picos de frequência de tendências para as temperaturas ocorreram na década de 1990: T-Máx. com 14 tendências, T-Mín. com 11 tendências e T-Méd. com 10 tendências. Na região Centro-Oeste (figura 9e) as temperaturas também apresentam picos de frequências na década de 1990, ressaltando-se a T-Mín. com 10 detecções de tendências. 


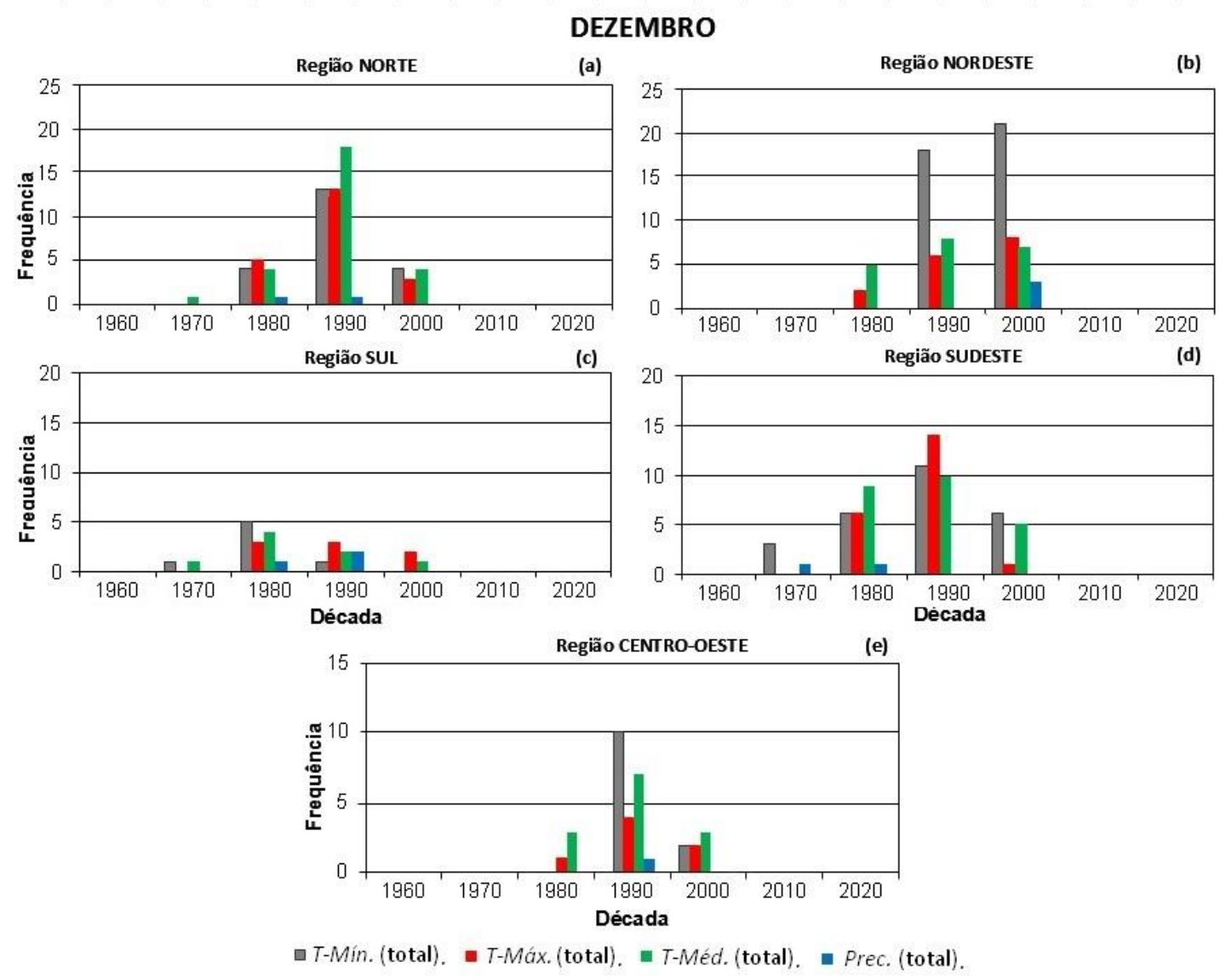

Figura 9 - Idem à figura anterior, porém para variáveis climáticas tratadas no mês de dezembro.

Os histogramas das Figuras 8 e 9 também revelam que entre 1961 e 1970 nenhuma tendência foi registrada nas temperaturas do ar e na precipitação, com exceção a uma única localidade na região Sudeste (Campos do Jordão, SP), que em junho de 1969 registrou tendência de aumento na $T$ Méd.

As análises desenvolvidas anteriormente mostram que o clima do território brasileiro, assim como em outras partes do planeta, é muito complexo, pois envolve controles internos e externos ao sistema terra-atmosfera-oceano, não sendo um aval para os seres humanos, como tem feito nas últimas décadas, em particular no Brasil, degradar o meio ambiente. Ao contrário, e em consonância com Zanquim Jr. et al., (2015), considerando que o aumento populacional nas próximas décadas é inevitável, sugere-se a adoção de políticas de conservação ambiental bem elaboradas e mudanças nos hábitos de consumo para que as gerações futuras possam dispor dos recursos naturais existentes atualmente.

Uma possível explicação para as tendências detectadas nas variáveis climáticas deste levantamento parece estar relacionada às características geográficas de cada região. Adicionalmente, deve-se reconhecer que a mudança na concepção da vida rural para a vida urbana proporcionou um 
desenvolvimento econômico-social e permitiu os avanços tecnológicos vivenciados. Porém, essa gama de elementos impulsionou crises ambientais, em especial nas regiões próximas de centros urbanos.

\section{CONCLUSÕES}

Dentro dos limites impostos pelos testes estatísticos utilizados e de acordo com a quantidade de séries temporais anuais tratadas neste levantamento para os meses de junho e dezembro, em termos gerais, os resultados apresentados indicaram que:

-. Respectivamente, ocorreram ausências de tendências significativas em $92,18 \%$ e $95,88 \%$ na precipitação pluviométrica (Prec.).

- Também para os meses de junho e dezembro, em vários locais abordados no presente levantamento, foram identificadas tendências de aumento nas temperaturas, sendo, respectivamente, para a T-Mín. 27,16\% e 34,16\%; para a T-Máx. 35,39\% e 27,98\% e para a T-Méd., 30,86\% e 35,39\%. Esses aumentos nas temperaturas foram registrados principalmente nas regiões Norte e Sudeste, no sul da região Nordeste e no norte da região Sul, em particular em localidades que na última década do século passado e na primeira década deste século acompanharam um aumento da zona urbana, seguido de desmatamentos e desenvolvimento agropecuário e industrial.

Vale lembrar que, buscar justificativas e explicações para ocorrências destas alterações nos municípios brasileiros, particularmente devido às ações antropogênicas ou causadas pela variabilidade natural do clima, ainda é um desafio para a ciência, principalmente com a dificuldade de se obter longos períodos de dados observacionais para estudos no Brasil.

Finalmente, pode-se dizer que os resultados apresentados neste trabalho chamam a atenção para os cuidados que se deve ter ao apontar que as causas das catástrofes naturais observadas atualmente em várias cidades brasileiras são devidas às alterações climáticas. Neste contexto, pode-se citar o aumento de tempestades e enchentes, secas prolongadas, intensificação da magnitude e da frequência de ocorrência de eventos extremos, dentre outras. Como consequências, essas ocorrências podem trazer não só danos ao meio ambiente em que se localiza uma determinada cidade, mas também danos à economia e à saúde das pessoas. Isso pode ser decorrente da complexidade em dissociar essas alterações às variações naturais do clima. No entanto, apesar das incertezas associadas às mudanças climáticas e, consequentemente, aos impactos dessas possíveis alterações do clima em séries temporais, como apresentado e discutido neste trabalho, estudos dessa natureza são relevantes e oportunos para auxiliar os gestores municipais no cenário atual de intenso questionamento e debate das questões ambientais.

\section{REFERÊNCIAS BIBLIOGRÁFICAS}

ALEXANDER, L. V.; ZHANG, X.; PETERSON, T. C.; CAESAR, J.; GLEASON, B.; TANK, A. M. G.; HAYLOCK, M.; COLLINS, D.; TREVIN, B.; RAHIMZADEH, F.; TAGIPOU, A.; RUPA KUMAR, K.; REVADEKAR, J.; GRIFFITHS, G.; VINCENT, L.; STEPHENSON, D.; BURN, J.; AGUILLAR, E.; TAYLOR, M.; NEW, M.; ZHAI, P.; 
RUSTICUCCI, M.; VASQUEZ-AGUIRRE, J. L. Global observed changes in daily climate extremes of temperature and precipitation. Journal of Geophysical Research, Bellingham, v. 111, p. 1-22, 2006.

ÁVILA, L. F.; MELLO, C. R.; YANAGI, S. N. M.; NETO, O. B. S. Tendências de temperaturas mínimas e máximas do ar no Estado de Minas Gerais. Pesquisa Agropecuária Brasileira, v. 49, n. 4, p. 247-256, 2014.

BACK, A. J. Aplicação de análise estatística para identificação de tendências climáticas. Pesquisa Agropecuária Brasileira, Brasília, v. 36, n. 5, p. 717-726, 2001.

BLAIN, G. C. Modeling extreme minimum air temperature series under climate change conditions. Ciência Rural, Santa Maria, v. 41, n. 11, p. 1877-1883, 2011.

BLAIN, G. C.; LULU, J. Absolut daily values of annual maximum and minimum air temperature series of the state of São Paulo, Brazil: trends, periodicities and associated probabilities. Revista Brasileira de Meteorologia, São José dos Campos, v. 26, n. 1, p. 29-40, 2011.

DOYLE, M. E.; BARROS, V. R. Attribution of the river flow growth in the Plata Basin. International Journal of Climatology, Reading, v. 31, n. 15, p. 2234-2248, 2011.

ETCCDI. Expert Team on Climate Change Detection and Indices. Comissão para Climatologia CCI/CLIVAR/JCOMM. Disponível em: <www.cccma.seos.uvic.ca/ETCCDMI/list_27_indices.html>. Acesso em: 02 set. 2016.

FREUND, J. E. Estatística Aplicada: Economia, Administração e Contabilidade. 11a. edição. Porto Alegre: Editora Bookman, 2006, 612 p.

GROPPO, J. D.; MORAES, J. M.; BEDUSCHI, C. E.; MARTINELLI, L. A. Análise de séries temporais de vazão e precipitação em algumas bacias do estado de São Paulo com diferentes graus de intervenções antrópicas. Geociências, Rio Claro, v. 24, n. 2, p. 181-193, 2005.

HAYLOCK, M. R.; PETERSON, T. C.; ALVES, L. M.; AMBRIZZI, T.; ANUNCIAÇÃO, Y. M. T.; BAEZ, J.; BARROS, V. R.; BERLATO, M. A.; BIDEGAIN, M.; CORONEL, G.; CORRADI, V.; GARGIA, V. J.; GRIMM, A. M.; KAROLY, D.; MARENGO, J. A.; MARINO, M. B.; MONCUNILL, D. F.; NECHET, D.; QUINTANA, J.; REBELLO, E.; RUSTICUCCI, M.; SANTOS, J. L.; TREBEJO, I.; VICENT, L. A. Trends in total and extreme South American rainfall in 1960-2000 and links with sea surface temperature. Journal of Climate, Washington, v. 19, p. 1490-1512, 2006.

IBGE. Instituto Brasileiro de Geografia e Estatística. Censo Demográfico de 2010. Disponível em: <www.cidades.ibge.gov.br/xtras/home.php>. Acesso em: 02 ago. 2016.

INMET. Instituto Nacional de Meteorologia. Banco de Dados para Pesquisa e Ensino - BDMEP. 2016. Disponível em: <www.inmet.gov.br>. Acesso em: 17 mai. 2016.

IPCC. Intergovernmental Panel on Climate Change 2007. Climate Change 2007: The Physical Science Basis. Contribution of Working Group I to the Fourth Assessment Report of the Intergovernmental Panel on Climate Change. 
SOLOMON, S., et al. (eds.). Cambridge University Press, Cambridge, United Kingdom and New York, NY, USA, 2007, 996 p. Disponível em: $<$ www.ipcc.ch/publications_and_data/publications_ipcc_fourth_assessment_rep ort_wg1_report_the_physical_science_basis.htm>. Acesso em: 04 ago. 2016.

IPCC. Intergovernmental Panel on Climate Change 2014: Summary for Policymakers. In: Climate Change 2014: Impacts, Adaptation, and Vulnerability. Field, C.B., et al. (eds.). Cambridge University Press, Cambridge, United Kingdom and New York, NY, USA, p. 1-32, 2014. Disponível em: <www.ipccwg2.gov/AR5/images/uploads/WG2AR5_SPM_FINAL.pdf>. Acesso em: 15 jun. 2016.

MARENGO, J. A. Mudanças climáticas e seus efeitos sobre a Biodiversidade: Caracterização do clima atual e definição das alterações climáticas para o Território Brasileiro ao longo do Século XXI. Series Biodiversidade, n. 26, MMA, 2007.

MARENGO, J. A.; CAMARGO, C. C. Surface air temperature trends in Southern Brazil for 1960-2002. International Journal of Climatology, Reading, v. 28, n. 7, p. 893-904, 2008.

MARENGO, J. A. O futuro clima do Brasil. Revistausp, n. 103, p. 25-32, 2014.

MORAES, J. M.; PELLEGRINO, G.; BALLESTER, M. V.; MARTINELLI, L. A.; VICTORIA, R. L. Estudo preliminar da evolução temporal dos componentes do ciclo hidrológico da bacia do Rio Piracicaba. In: XI Simpósio Brasileiro de Recursos Hídricos; II Simpósio de hidráulica e recursos hídricos dos países de língua oficial portuguesa. 1995. Anais... Recife: Associação Brasileira de Recursos Hídricos. 1995, p. 27-32, 1995.

PBMC. Painel Brasileiro de Mudanças Climáticas. Sumário Executivo: Base Científica das Mudanças Climáticas. Contribuição do Grupo de Trabalho 1 ao Primeiro Relatório de Avaliação Nacional do Painel Brasileiro de Mudanças Climáticas. 2013. Disponível em: <http://www.pbmc.coppe.ufrj.br/documentos/MCTI_PBMC_Sumario\%20Executi vo\%204_Finalizado.pdf>. Acesso em: 23 mai. 2016.

PENEREIRO, J. C.; MARTINS, L. L. S.; BERETTA, V. Z. Identificação de variabilidades e tendências interanuais em medidas hidro-climáticas na região hidrográfica do Tocantins-Araguaia, Brasil. Revista Brasileira de Climatologia, Curitiba, v. 18, n. 1, p. 219-241, 2016.

PETTITT, A. N. A non-parametric approach to the change-point problem. Applied Statistics, London, v. 28, n. 2, p. 126-135, 1979.

PICKERING, N. B.; HANSEN, J. W.; JONES, J. W.; WELLS, C. M.; CHAN, V. K.; GODWIN, D. C. Weather Man: A utility for managing and generating daily weather data. Agronomy Journal, Madison, v. 86, p. 332-337, 1994.

PINHEIRO, A.; GRACIANO, R. L. G.; SEVERO, D. L. Tendência das series temporais de precipitação da região sul do Brasil. Revista Brasileira de Meteorologia, São José dos Campos, v. 28, n. 3, p. 281-290, 2013.

SALVIANO, M. F.; GROPPO, J. D.; PELLEGRINO, G. Q. Análise de tendências em dados de precipitação e temperatura no Brasil. Revista Brasileira de Meteorologia, São José dos Campos, v. 31, n. 1, p. 64-73, 2016. 
SANSIGOLO, C. A.; KAYANO, M. T. Trends of seasonal maximum and minimum temperatures and precipitation in Southern Brazil for the 1913-2006 period. Theoretical and Applied Climatology, Vienna, v. 101, n. 1-2, p. 209-216, 2010.

SANSIGOLO, C. A.; NERY, J. T. Distribuição de extremos de temperatura mínima no estado do Paraná. Revista Brasileira de Agrometeorologia, Santa Maria, v. 8, n. 2, p. 247-253, 2000.

SANSIGOLO, C. A.; RODRIGUEZ, R. C. M.; ETCHICHURY, P. C. Tendências nas temperaturas médias do Brasil. In: VII Congresso Brasileiro de Meteorologia. 1992. Anais... São Paulo: Sociedade Brasileira de Meteorologia. 1992. p. 367$371,1992$.

SILVA, W. L.; DERECZYNSKI, C.; CHANG, M.; FREITAS, M.; MACHADO, B. J.; TRISTÃO, L.; RUGGERI, J. Tendências observadas em indicadores de extremos climáticos de temperatura e precipitação no estado do Paraná. Revista Brasileira de Meteorologia, v. 30, n. 2, p. 181-194, 2015.

SNEYERS, R. Sur I'analyse statistique dês séries d'observations. Genève: Organisation Météorologique Mondial, OMM Note Technique. n. 143, 1975, 192 p.

THOM, H. Some methods of climatological analysis. Secretary of OMM, Genebra, Suisse, Technical Note no. 81, OMM No. 199, TP 103, p. 1-11, 1971.

VENEGAS, S. A.; MYSAK, L. A.; STRAUB, D. N. Evidence for interannual and interdecadal climate variability in the South Atlantic. Geophysical Research Letters, v. 23, n. 19, p. 2673-2676, 1996.

VENEGAS, S. A.; MYSAK, L. A.; STRAUB, D. N. Atmosphere-ocean coupled variability in the South Atlantic. Journal of Climate, v. 10, p. 2904-2920, 1997.

VINCENT, L. A.; PETERSON, T. C.; BARROS, V. R.; MARINO, M. B.; RUSTICUCCI, M.; CARRASCO, G.; RAMIREZ, E.; ALVES, L. M.; AMBRIZZI, T.; BERLATO, M. A.; GRIMM, A. M.; MARENGO, J. A.; MOLION. L.; MONCUNILL, D. F.; REBELLO, E.; ANUNCIAÇÃO, Y. M. T.; QUINTANA, J.; SANTOS, J. L.; BAEZ, J.; CORONEL, G.; GARCIA, J.; TREBEJO, I.; BIDEGAIN, M.; HAYLOCK, M. R.; KAROLY, D. Observed trends in indices of daily temperature extremes in South America 1960-2000. Journal of Climate, Boston, v. 18, p. 5011-5023, 2005.

ZANQUIM JR., J. W.; MORAES, A. P. H.; MORAES, F. T.; MELNICKY, E. C. C. Danos ambientais urbanos e instrumentos de solução dos conflitos. In: Novos Direitos - Cidades em Crise? 2015. Anais... São Carlos: Editora RiMa, p. 175188,2015 